\title{
ERRATUM
}

\section{LISADEMAS: A Life Satisfaction Decision-Making System for Integrated Community Development Planning}

\section{Vaios Kotsios}

(C) Springer Science+Business Media Dordrecht 2017

R. Phillips, C. Wong (eds.), Handbook of Community Well-Being Research, International Handbooks of Quality-of-Life, DOI 10.1007/978-94-024-0878-2

\section{DOI 10.1007/978-94-024-0878-2_32}

Incorrect figure 19.4 was used in the previous version. However this has been replaced to the one below.

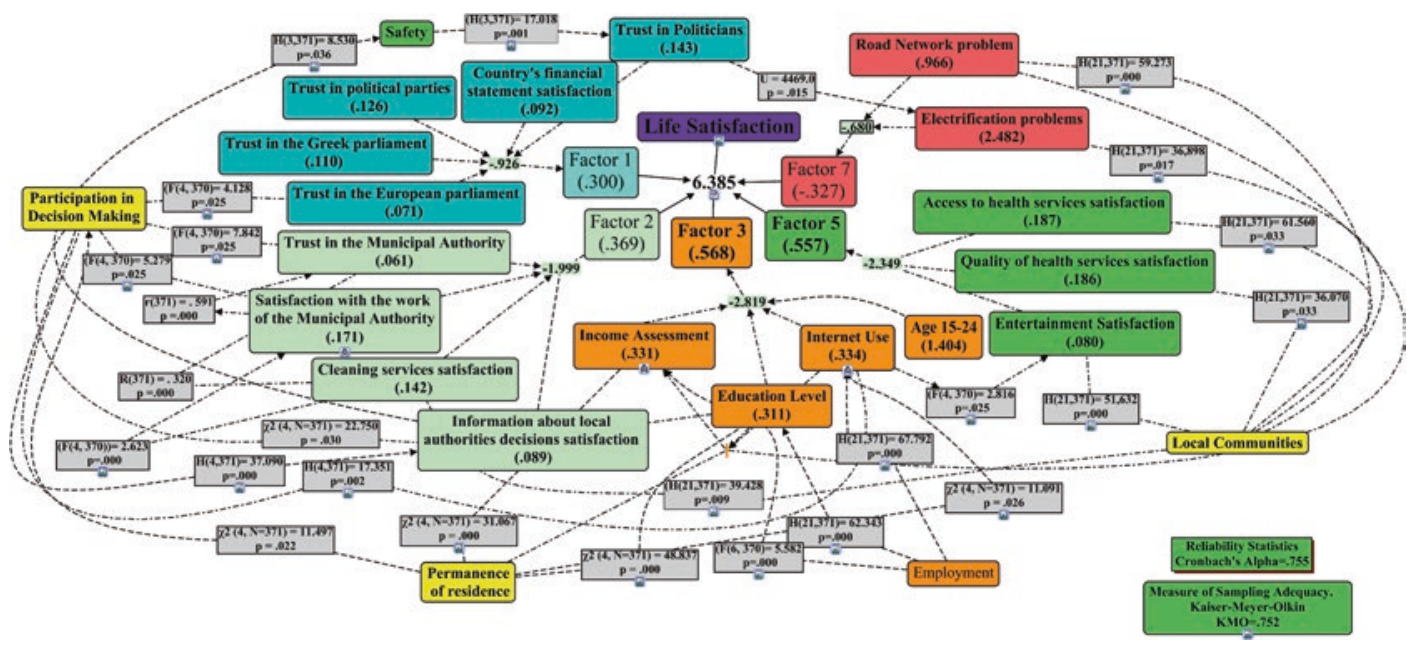

Fig. 19.4 Conceptual framework 